\title{
Elderly comfort and compliance to modern telemedicine system at home
}

\author{
Yousef Jasemian \\ Health Science \& Technology, Pervasive Healthcare lab. \\ Engineering College of Aarhus, Denmark \\ yj@iha.dk
}

\begin{abstract}
-the success of integration and adaptation of pervasive computing and telemedicine technology in healthcare depends on the patients' compliance and trust to the introduced system.

The aims of the present paper are to investigate, verify and evaluate the elderly heart patients' (EHP) compliance, trust and comfort in relation to a real-time wireless telemedicine system at home. A telemedicine system composed of a patient-unit, a GSM/GPRS network, a router, a data interpreter and a monitoring system was used. Twenty four non risky EHPs, aged $(60 \pm 5)$ years were recruited. A week of continuous ECGs for each of the EHPs were recorded. The experiments were carried out while the EHPs were performing their every day's activities. The EHPs' compliance, trust and comfort was verified and evaluated by three questionnaires. In average, $52 \%$ of the EHPs scored the user-friendly and usability of the system as reasonable.

Only $16 \%$ sought help from the healthcare personnel in respect with the application of the patient-unit. $76 \%$ scored the reliability of the system as "reasonable" and $20 \%$ as "only now and then". It is concluded that the present system is reliable, functions with a clinically acceptable performance. The EHPs have expressed reasonable compliance and trust to the application of the system at home; however a number of the elderly were not satisfied with the weight and the user-interface of the ECG device.
\end{abstract}

Keywords- pervasive healthcare, elderly patients, elderly compliance, elderly trust, patients' comfort, telemedicine, heart patients

\section{INTRODUCTION}

Government and research statistics, obviously, show that age distribution in many Western countries is shifting dramatically towards an older population. Older people have different requirements from society and government as opposed to young people, and frequently differing values as well. These issues alone will have an enormous impact on the demands for care services for the elderly. Nowadays, in many Western countries, the health authorities tend to optimise the resources most effectively by introducing pervasive healthcare services, where it is in many cases an option to treat/monitor as many patients as possible at their home.

This is an important issue when people with disabilities and elderly people are considered. Thanks to emerging technologies the elderly now have the opportunity to stay in their homes longer and manage everyday tasks without significant burden for their caregivers. Pervasive computing in Smart Homes are an examples of using intelligent devices to improve the quality of life for disable people and elderly. Guides showing the shortest route from one place to another [1] or helping with a task by giving step-by-step instructions [1], devices monitoring time and amount of medication taken [2], robotic interfaces combined with virtual-reality environments for rehabilitation [3], applying an ordinary mobile phone, Bluetooth technology and public cellular network for wireless remote monitoring heart patient in real-time [4] [5] are other examples of emerging pervasive computing technologies. Many home monitoring systems have been designed and developed, and various issues have been reviewed in depth [4] [6] [7] [8] [9] [10] [11].

Pervasive (or ubiquitous) computing technology for healthcare covers a wide range of areas; such as distributed and mobile computing, artificial intelligence, sensor networks, and human-computer interaction. Researchers and developers need to combine knowledge of all of these disciplines to design and develop systems that are safe, secure, reliable, user-friendly and truly accessible to users. They need to combine knowledge from medicine, physiotherapy, psychology, and information and communications technology (ICT) as well in order to create more user-centred systems. Pervasive computing techniques have been applied in clinical settings [12] [13]. There has been little research on pervasive computing for healthcare at home, though some projects are investigating the transmission of the patient's medical data to a care centre [14], and other paper validates a real-time wireless telemedicine system for remote monitoring patient at home [15].

The success of integration and adaptation of pervasive computing and telemedicine technology in patient's home depends on the patients' compliance and trust to the introduced system. Trust is a composition of many different attributes; reliability, dependability, honesty, truthfulness, security, competence, timeliness and comfort, which may have to be considered depending on the environment in which trust is being specified. 
The Compact Oxford English Dictionary [16] states that trust is "firm belief in the reliability, truth, ability, or strength of someone or something". A trustworthy entity will typically have a high reliability and so will not fail during the course of an interaction, will perform a service or action within a reasonable period of time, will tell the truth and be honest with respect to interactions and will not disclose confidential information. Competence is a better term than strength for the environment related to services and computing system, i.e. an entity should be capable of performing the functions expected of it or the service it is meant to provide correctly and within reasonable timescales. Thus, wining patients' compliance and trust will be a challenge.

\section{MOTIVATION}

In Aalborg hospital (Denmark) $40 \%$ of the total number of cardiac patients are hospitalised due to heart arrhythmia, most of them are elderly. These patients are all monitored by shortrange telemetry in the hospital for one to five days (patient registration section, Aalborg Hospital, Denmark). Non-risky heart patients are sent home to be monitored by Holter or event recording devices (off-line monitoring devices). Not all elderly patients show high compliance with the application of these devices, as this function off-line. Nor this monitoring arrangement provides comfort to the elderly patients.

\section{SPECIFIC AIMS}

The aims of the present paper are to investigate, verify and evaluate the elderly patients' compliance, trust and comfort in relation to a real-time wireless telemedicine system at home.

\section{MATERIALS AND METHODS}

A telemedicine system composed of a patient-unit (Danica Biomedical T3300 ECG device, a Bluetooth module and a Sony Ericsson T610 mobile phone, Denmark), GSM/GPRS network (SONOFON, Denmark), a router, a data interpreter and a monitoring system (Figure1) were used [4] [5]. Twenty four non risky elderly heart patients, aged $(60 \pm 5)$ years (12 males and 12 females), were included.

A week of continuous ECGs for each of the elderly were recorded. The experiments were carried out while the elderly, wearing the patient-unit, were performing their every day's indoors and outdoors activities. They were instructed how to mount the disposable electrodes, how to operate the patientunit and how and when they should change/ recharge the batteries. They were asked not to shower while wearing the patient-unit. The elderly had a fixed telephone line at home and were equipped with an extra mobile phone when they were out of doors. They were contacted in case there was any problem. The patients were asked to keep a diary of their daily activities.

To evaluate the elderly compliance, trust and comfort in respect to the present telemedicine system, three self registered questionnaires were designed and prepared. The first one for the evaluation of the system's degree of user-friendly, usability and reliability, the second one for the evaluation of the patients' privacy, freedom and mobility during monitoring period, the third one for the evaluation of the patients' degree of confidence and trust in respect of using the present wireless remote monitoring system at home.

\section{A. System's functionality}

A telemetry device collects the ECGs from the patient's chest via 4 disposable electrodes. The telemetry device is connected to a Bluetooth module via a serial interface. The Bluetooth module is wirelessly connected to a mobile phone (figure 1). The Bluetooth module is designed to invoke the mobile phone to establish either a GSM or a GPRS connection automatically. The transmission of the data, from the mobile phone to the server at the hospital, is carried out via GSM/GPRS network. On hospital side the interpreter receives the data through a router and converts it to pre-defined format. The data are sent to the monitoring system via serial cable. The monitoring system converts the received data to graphical ECG [4] [5]. The mobile phone is connected in the course of the real-time monitoring period. In case of network failure or no GSM/GPRS network coverage, the Bluetooth module via mobile phone, repeatedly attempts for connection reestablishment until a complete connection is established. The system is equipped with alarm procedure, and gets benefit of the integrated data security arrangements in Bluetooth, GSM and GPRS [17].

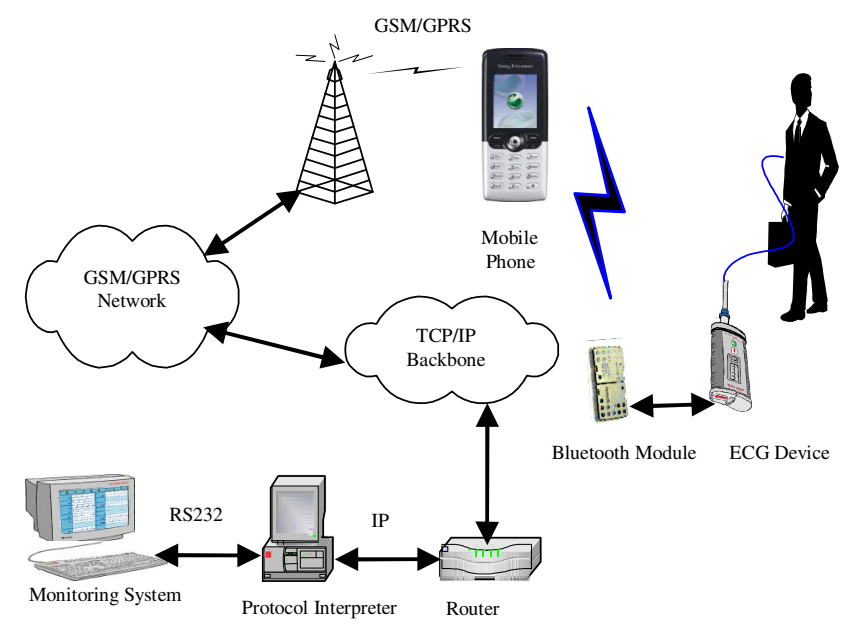

Figure 1. a principal sketch of the wireless remote patient monitoring system containing ECG device, Bluetooth module, mobile phone, GSM/GPRS network, router, data interpreter and a graphical ECG monitoring system. 


\section{RESULTS}

\section{A. System's user-friendly, usability and reliability}

The elderly spent $(15 \pm 3)$ minutes to learn how to use the patient-unit. In average, $80 \%$ of the elderly scored the userfriendly and usability of the system as good. The majority (92 $\%$ ) could easily manage employing the system. Only $16 \%$ of the elderly sought help from the healthcare personnel in relation to employment of the patient-unit, and few (4\%-8\%) had problem with changing or re-charging batteries for the mobile phone and ECG device as well. $76 \%$ of the elderly $(\mathrm{n}=$ 24) scored the reliability of the system as "reasonable", $20 \%$ as "only now and then", and only $4 \%$ scored the reliability as "excellent". The results are summarised in table 1.

TABLE I. SYSTEM'S USER-FRIENDLY, USABILITY AND RELIABILITY

\begin{tabular}{|c|c|c|}
\hline Table 1 & \multicolumn{2}{|c|}{ The scores } \\
\hline $\begin{array}{l}\text { How long (in minutes) did it take for you to } \\
\text { learn to use the patient-unit? }\end{array}$ & \multicolumn{2}{|c|}{$15 \pm 3$ minutes } \\
\hline \multirow{4}{*}{$\begin{array}{l}\text { Express the degree of complexity using the } \\
\text { mobile phone } \\
(0=\text { not at all, } 1=\text { a little, } 2=\text { some times, } 3= \\
\text { very much })\end{array}$} & $72 \%$ & "0" \\
\hline & $20 \%$ & "1" \\
\hline & $4 \%$ & " $2 "$ \\
\hline & $4 \%$ & “3”, \\
\hline \multirow{4}{*}{$\begin{array}{l}\text { Express the degree of complexity using the } \\
\text { telemetry device } \\
(0=\text { not at all, } 1=\text { a little, } 2=\text { some times, } 3= \\
\text { very much) }\end{array}$} & $60 \%$ & "0" \\
\hline & $20 \%$ & "1" \\
\hline & $12 \%$ & “2” \\
\hline & $8 \%$ & “3” \\
\hline \multirow{2}{*}{$\begin{array}{l}\text { Could you manage employing the system at } \\
\text { home? }\end{array}$} & $92 \%$ & "yes" \\
\hline & $8 \%$ & "no" \\
\hline \multirow[t]{3}{*}{ Did you change the electrodes by yourself? } & $8 \%$ & "no" \\
\hline & $42 \%$ & "once" \\
\hline & $50 \%$ & "twice" \\
\hline \multirow{3}{*}{$\begin{array}{l}\text { Did you have difficulty changing the } \\
\text { electrodes? }(0=\text { not at all, } 1=\text { a little, } 2= \\
\text { some times, } 3=\text { very much })\end{array}$} & $84 \%$ & "0" \\
\hline & $8 \%$ & "1" \\
\hline & $8 \%$ & "3" \\
\hline \multirow{3}{*}{$\begin{array}{l}\text { Did you need help from the healthcare } \\
\text { personnel for using the system at home? }(0= \\
\text { not at all, } 1=\text { a little, } 2=\text { some times, } 3=\text { very } \\
\text { much) }\end{array}$} & $84 \%$ & "0" \\
\hline & $12 \%$ & "1" \\
\hline & $4 \%$ & “2” \\
\hline \multirow{3}{*}{$\begin{array}{l}\text { Did you have difficulty changing batteries for } \\
\text { the mobile phone? }(0=\text { not at all, } 1=\text { a little, } 2 \\
\text { = some times, } 3=\text { very much })\end{array}$} & $84 \%$ & “0” \\
\hline & $8 \%$ & "1" \\
\hline & $8 \%$ & “2” \\
\hline \multirow{3}{*}{$\begin{array}{l}\text { Did you have difficulty changing batteries for } \\
\text { the ECG device? }(0=\text { not at all, } 1=\text { a little, } 2= \\
\text { some times, } 3=\text { very much })\end{array}$} & $84 \%$ & “0” \\
\hline & $12 \%$ & "1" \\
\hline & $4 \%$ & “2” \\
\hline \multirow{4}{*}{$\begin{array}{l}\text { Do you think the patient unit is heavy? }(0= \\
\text { not at all, } 1=\text { a little, } 2=\text { some times, } 3=\text { very } \\
\text { much) }\end{array}$} & $68 \%$ & “0” \\
\hline & $4 \%$ & "1" \\
\hline & $8 \%$ & “2” \\
\hline & $20 \%$ & "3" \\
\hline \multirow{3}{*}{$\begin{array}{l}\text { Did the system work properly? } \\
(0=\text { not at all, } 1=\text { only now and then, } 2= \\
\text { reasonable, } 3=\text { excellent })\end{array}$} & $20 \%$ & "1" \\
\hline & $76 \%$ & " $2 "$ \\
\hline & $4 \%$ & “3” \\
\hline
\end{tabular}

\section{B. Patients' privacy, freedom and mobility}

The majority of the elderly believed that their expectation to privacy was in $84 \%$ fulfilled. And only $4 \%$ believed that their expectation to privacy was only now and then fulfilled. Almost $52 \%$ of the elderly patients $(\mathrm{n}=24)$ scored for a reasonable mobility and freedom, and the rest $20 \%$ scored for not complete fulfillment of freedom and mobility. The results are summarised in table 2 .

TABLE II. PATIENTS' PRIVACY, FREEDOM AND MOBILITY

\begin{tabular}{|c|c|c|}
\hline Table 2 & \multicolumn{2}{|c|}{ The scores } \\
\hline $\begin{array}{l}\text { How do you evaluate your privacy being monitored by } \\
\text { the present remote monitoring system at home? } \\
(0=\text { was not fulfilled at all, } 1=\text { only now and then was } \\
\text { fulfilled, } 2=\text { reasonably fulfilled, } 3=\text { completely } \\
\text { fulfilled })\end{array}$ & $\begin{array}{c}4 \% \\
84 \% \\
12 \%\end{array}$ & $\begin{array}{l}\text { "1" } \\
\text { "2" } \\
\text { " } 3 \text { " }\end{array}$ \\
\hline $\begin{array}{l}\text { How do you evaluate your mobility being monitored } \\
\text { by the present wireless remote monitoring system at } \\
\text { home? } \\
(0=\text { not at all, } 1=\text { only now and then, } 2 \text { = reasonable, } 3 \\
=\text { excellent })\end{array}$ & $\begin{array}{l}20 \% \\
52 \% \\
28 \%\end{array}$ & $\begin{array}{l}\text { "1" } \\
\text { "2" } \\
\text { " } 3 \text { " }\end{array}$ \\
\hline $\begin{array}{l}\text { How do you evaluate your freedom being monitored by } \\
\text { the present wireless remote monitoring system at } \\
\text { home? } \\
(0=\text { not at all, } 1 \text { = only now and then, } 2 \text { = reasonable, } 3 \\
=\text { excellent })\end{array}$ & $\begin{array}{l}16 \% \\
54 \% \\
38 \%\end{array}$ & $\begin{array}{l}\text { "1" } \\
\text { "2" } \\
\text { " } 3 "\end{array}$ \\
\hline
\end{tabular}

\section{Patient's trust, comfort and compliance}

Only $12 \%$ of the elderly patients do not trust the present wireless remote monitoring system at all, whereas $72 \%$ trust the system. More than $60 \%$ of the elderly are used to employ a mobile phone in daily life and $50 \%$ have a reasonable understanding of the system application. $80 \%$ believe that their comfort is satisfied. Eighteen out of twenty four elderly patients $(76 \%)$ preferred to be monitored from their home (in more natural environments). The results are summarised in table 3 .

\section{TABLE III. PATIENTS' TRUST, COMFORT AND COMPLIANCE}

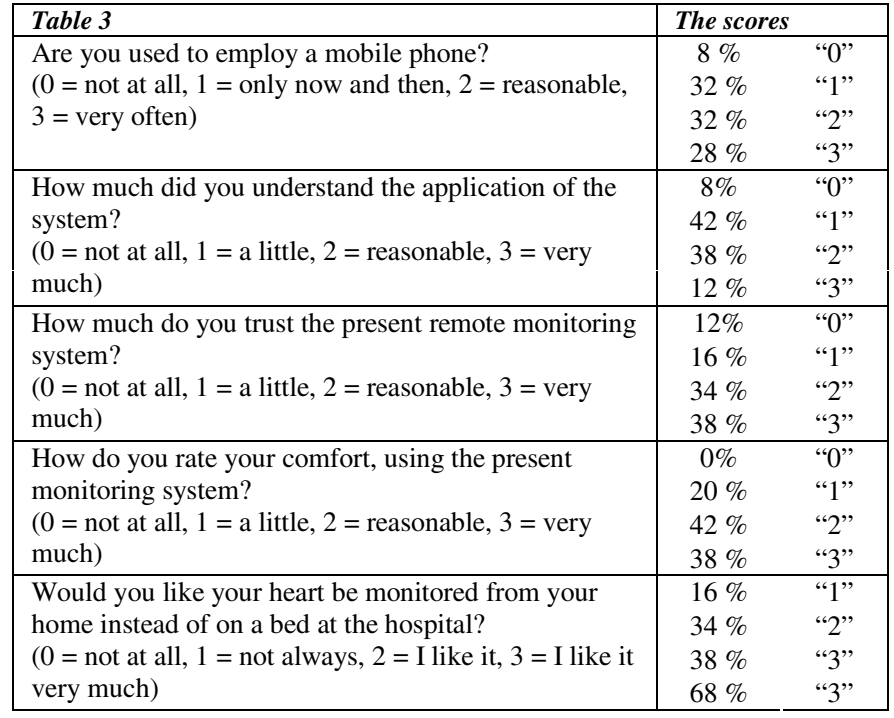

\section{DISCUSSION AND CONCLUSION}

The elderly patients' compliance, trust and comfort in relation to a real-time wireless telemedicine system at home were investigated. In this connection, the patient's mobility, 
freedom, trust and compliance in addition to the system's userfriendly and reliability were verified and evaluated. The results showed that the present system is reliable, functions with a clinically acceptable performance, even though the system was tested under totally uncontrolled circumstances while the patients' were performing their daily activities indoors and outdoors. The elderly patients have expressed reasonable compliance and trust to the application of the system at home; the more natural environment. The majority believe that their comfort was satisfied. However, a number of the elderly were not satisfied with the weight and user interface of the ECG device. These issues bring up an important principal approach in a system design and development, namely patients' satisfaction relies on a more user-driven design and development.

The results could not be generalised to elderly population, as the number $(n=24)$ of the recruited elderly patients are not completely representing the general population. Furthermore, the present investigation has been performed only in respect with one specific telemedicine system and should be applied on a number of similar systems in order to have a better picture of the general attitude of the elderly in the population.

Finally, it could be concluded, that the system is applicable for patient monitoring and aftercare in elderly patients' home and the elderly are reasonably confident in using it. However, the patient-unit should be designed more user-friendly. This subject needs further investigation in a larger scale.

\section{REFERENCES}

[1] H. Kautz, L. Arnstein, G. Borriello, O. Etzioni, and D. Fox, "An overview of the assisted cognition project," in AAAI'02: Proceedings of workshop on Automation as Caregiver: The Role of Intelligent Technology in Elder Care, July 2002.

[2] R. Jafari, F. Dabiri, P. Brisk, and M. Sarrafzadeh, "Adaptive and fault tolerant medical vest for life-critical medical monitoring," in SAC '05: Proceedings of the 2005 ACM symposium on Applied computing. ACM Press, Mar. 2005, pp. 272-279.

[3] M. K. Holden, "Virtual environments for motor rehabilitation: Review," Cyberpsychology \& behavior, 2005, vol. 8, no. 3, pp.187-211.

[4] Y. Jasemian and L. Arendt-Nielsen, "Design and implementation of a telemedicine system using BLUETOOTH and GSM/GPRS, for real time remote patient monitoring". The International Journal of Health Care Engineering 2005, volume 13, pp. 199-219.

[5] Y. Jasemian and L. Arendt-Nielsen, "Evaluation of a real-time, remote monitoring telemedicine system, using the Bluetooth protocol and a mobile phone network, Journal of Telemedicine and Telecare 2005, volume 11 , No. 5, pp. 256-260.

[6] M. Ackerman, R. Craft, F. Ferrante, M. Kratz, S. Mandil, and H. Sapci, "Telemedicine technology," Telemedicine Journal and e-Health 2002, volume 8 , no. 1 ,

[7] U. Varshney, "Using wireless networks for enhanced monitoring of patients," in Proceedings of the tenth Americas conference on information systems, New York, 2004.

[8] R. Lee, H. Shen, C. Lin, K. Chang, and J. Chen, "Home telecare system using cable television plants, an experimental field trial," IEEE Transactions on Information Technologies in Biomedicine 2000, vol. 4, no. 1 , p. 3744 .

[9] P. S, "A novel emergency telemedicine system based on wireless communication technology," IEEE Trans Inf Technol Biomed 1998, vol. 2, p. 261267.

[10] T. . Bui and Sankaran, "Group decision and negotiation support in telemedicine: An application of intelligent mobile agents as non-human teleworkers," in Proceedings of the 30th Hawaii International Conference on System Sciences, 1997, pp. 120-129.

[11] K. Z. Haigh and H. A. Yanco, "Automation as caregiver: A survey of issues and technologies," in Proceedings of AAAI 2002 Automation as Caregivers, pp. 39-53.

[12] J. E. Bardram. Applications of ContextAware Computing in Hospital Work - Examples and Design Principles, Proc. ACM SAC '04, Nicosia, Cyprus, Mar. 2004.

[13] M. Drugge, J. Hallberg, P. Parnes, and K.Synnes. Wearable Systems in Nursing Home Care: Prototyping Experience, IEEE Pervasive Computing Jan.-Mar. 2006, 5(1):86-91,.

[14] J. E. Bardram. The Personal Medical Unit - A Ubiquitous Computing Infrastructure for Personal Pervasive Healthcare. In T. Adlam, H. Wactlar, and I. Korhonen, eds., Proc. 3rd. Ubiquitous Computing for Pervasive Healthcare Applications, Nottingham, UK, Sep. 2004.

[15] Y. Jasemian and L. Arendt-Nielsen, "Validation of a real-time wireless telemedicine system, using bluetooth protocol and a mobile phone, for remote monitoring patient in medical practice." Eur J Med Res. 2005 Jun 22;10(6):254-62.

[16] Compact Oxford English Dictionary, free internet access, September 2007, available http://www.askoxford.com/concise_oed/trust?view=uk

[17] Y. Jasemian, "Security and privacy in a wireless remote medical system for home healthcare purpose", Page(s): 1-7, Proc. PHC, Digital Object Identifier 10.1109/PCTHEALTH. 2006.361658, available on: http://ieeexplore.ieee.org/xpl/tocresult.jsp?isnumber=4205140\&isYear= 2006 